\title{
CIENCIA Y PSEUDOCIENCIA EN LOS MEDIOS DE COMUNICACION
}

\author{
Dr. Manuel Carreira, 8.j.
}

La realidad del Hombre, con sus diversos niveles de actividad, implica también una diversidad de necesidades. Como todo organismo viviente, sujeto a desgaste $y$ que requiere un ambiente adecuado para su desarrollo y funcionamiento, tiene necesidades de orden material; alimento, cobijo, salud. Deben satisfacerse con la ayuda de otros, y esto exige un grado mínimo de comunicación; deben también utilizarse recursos más o menos lejanos y que requieren elaboración: tecnología y medios de transporte son consecuencias, al menos en parte, del deseo de cubrir las deficiencias del entorno inmediato para poder sobrevivir.

Pero lo específico del Hombre es su actividad de nivel intelectual, artístico y afectivo: la búsqueda de Verdad, Belleza y Bien. Este mundo del espíritu no puede desarrollarse sino con medios de expresión que nos permiten articular nuestros pensamientos y que nos dan acceso a los logros culturales de otros, coetáneos o presentes en sus obras después de su muerte. Solamente el Hombre posee un lenguaje variado, expresivo, capaz de significado desde la designación de un objeto concreto hasta las ideas más abstractas de la filosofia o de la concepción poética. Nuestra comunicación de todo este mundo inmaterial nos permite adquirir datos, entrever o establecer relaciones, encontrar orden, y hacer a otros partícipes de nuestros esfuerzos, mientras nos beneficiamos de lo conseguido por nuestros semejantes de todo tiempo y lugar durante la historia humana. Sólo el Hombre aumenta su acervo de conocimientos por este proceso.

La expresión cultural se realiza por medios visuales en las artes -pintura, escultura, arquitectura, en todas sus formas variantes- y en la palabra escrita. Son medios sonoros la música, la palabra hablada, el canto que combina a ambas. Si la palabra es el modo más directo de comunicar lo abstracto, el mundo de las ideas, ya sea en forma oral o escrita, las imágenes en todas sus formas y los sonidos de una canción pueden tener un impacto más profundo en lo afectivo, lo inconsciente, el mundo de las emociones que son motores de actividad. En este nivel se repite el 
adagio de que una imagen vale más que mil palabras, y que toda mera predicación verbal queda desvirtuada por un ejemplo de vida contrario.

No hay verdadera cultura sino en el conjunto de ideas que explican y dan sentido a la realidad externa e interna: la propia persona, la sociedad, el mundo de la naturaleza, Dios. De la concepción de cada pueblo respecto a estos grandes temas universales nacen las estructuras sociales y políticas, el Derecho, el Arte, la Filosofia, la Literatura: todas las manifestaciones culturales que se muestran con orgullo como testimonio de lo más valioso de cada grupo humano. A este nivel de ideas configurativas de la sociedad y la persona es donde pueden encontrarse los valores dignos de mantenerse como expresión de una identidad nacional; no es cuestión de un detalle estilístico en la cerámica o en la arquitectura para definir una "cultura" concreta en vitrinas de museo.

Hablamos, consecuentemente, de "cultura griega", "cultura azteca", "cultura cristiana", que no deben identificarse con preferencias artísticas ni con costumbres más o menos arraigadas en su historia, sino con las concepciones humanas y religiosas que daban sentido a su vida. Si el decir que todas las culturas deben ser apreciadas implica que todas las concepciones de todos los pueblos respetaron o respetan por igual la dignidad humana, tal afirmación es claramente una falacia. Como lo seria el decir que hay que proteger la "cultura de la droga" o la de regímenes o grupos fundados sobre la esclavitud y la violencia.

Como expresión de valores compartidos en un entorno social, la cultura exige comunicación, y su nivel medio en una sociedad depende del grado en que se comunican y hacen parte de la vida de cada ciudadano las ideas y modos de proceder propios de su visión. Comenzando con la tribu, se extiende la interpretación de la realidad a la ciudad-estado, a la nación, a la humanidad, con ámbito creciente de difusión de ideas compartidas. Al mismo tiempo, dentro de cada grupo, hay diversos niveles de profundidad, en la cultura popular de campesinos, de las ciudades, del entorno universitario. Y se puede especificar un campo concreto donde el flujo de información, de ideas e intereses, es especialmente activo; la temática propia permite hablar de cultura histórica, literaria, artística, científica, filosófica o teológica. En todos los casos, no hay cultura sin medios de comunicación: aun cuando hablamos de la cultura de una persona nos referimos a conocimientos y actividades que no se limitan al propio esfuerzo mental o experiencia externa, sino que son recibidos y compartidos en un entorno más o menos amplio. 


\section{Medios de comunicación: desarrollo histórico}

La comunicación oral, la más común en épocas primitivas de todas las sociedades, alcanzó niveles asombrosos en poesía y en la diseminación de ideas mítico-religiosas e históricas: basta recordar a Homero. Todavía tiene importancia primordial en muchas sociedades casi tribales, en las islas del Pacífico o en partes más aisladas de África o Asia; la predicación hablada de los Apóstoles y sus sucesores transformó el mundo greco-romano, y trovadores y juglares medievales Ilevaron por toda Europa el saber y las ideas de una Cristiandad que compartía la cultura básica del Evangelio, con matices propios de cada pueblo o nación.

Aun cuando la escritura se convirtió en el medio por excelencia para difundir ideas y para llegar a formas estabilizadas de ámbito amplio y alcance independiente del tiempo, durante la mayor parte de la historia humana las grandes masas han sido iletradas. Escribas, instruidos para recoger datos, leyes y hechos importantes, $y$ únicos capaces también de interpretar lo escrito, eran funcionarios civiles, al servicio de un rey o una administración política, económica y religiosa. El pueblo en su mayoría seguía instruyéndose con la palabra hablada y con la ayuda visual de estatuas, pinturas, vidrieras: eran las catedrales la Biblia del pueblo que no sabía leet. No es raro encontrar indicaciones, en épocas aun recientes, de una cierta veneración supersticiosa de la palabra escrita, con amuletos hechos de frases misteriosas, que por ser producto de un conocimiento reservado a muy pocos parecían especialmente dotados de poder sobrenatural.

La invención y difusión de la imprenta hizo posible, por primera vez, utilizar un medio de comunicación adecuado para alcanzar a una gran parte de la sociedad. El libro deja de ser una obra de arte, cada ejemplat casi único y de precio prohibitivo, para convertirse en parte normal de la vida diaria de todos los ciudadanos, aun los de medios económicos muy limitados. Cada vez son menos aquellos que no saben leer y escribir; el periódico diatio es, en forma creciente en los dos áltimos siglos, el moldeador y reflejo de corrientes ideológicas que transforman la sociedad. Aun cuando el telégrafo, teléfono y telex ( $\mathrm{y}$ ahora Internet) dan acceso inmediato a noticias y personas de todo el mundo, es en las páginas de diarios y revistas donde se difunden los puntos de vista, los valores y los intereses de la sociedad de cada nación.

Con la radio, se añade un nuevo medio de difusión dirigido a las masas, a la casi totalidad de los ciudadanos, llegando a ellos en la intimidad de su hogar y afectándolos en su conocimiento, su emotividad, su búsqueda de placer. Es otra vez la palabra hablada, acompañada de música, y recursos sonoros dramáticos, la que moldea ambientes culturales tan amplios que nadie se escapa a su influjo, 
incluso inconsciente: solamente durante el sueño está libre el individuo de la continua presencia de noticias, mensajes comerciales, comentarios de opinión. La propaganda de radio fue considerada un arma importante durante los conflictos armados del siglo veinte, $y$ eran las emisoras un blanco apetecido para las acciones bélicas: la "moral"del enemigo podía depender del silencio o actividad de una emisora. La "cultura de masas" se hace más palpable con la utilización del cine: la imagen activa, unida luego a la palabra y la música, crea un nuevo arte de comunicación directa dirigido a las masas, no a una minoria selecta de las academias renacentistas o de la aristocracia. En el cine se reflejan los problemas sociales, la lucha de clases, los conflictos locales o internacionales, las ideas religiosas, los avances cientificos con sus promesas y sus amenazas implicitas. Se hace tópico el "científico loco", con su secuela de monstruos (Frankenstein, robots, invasores extra-terrestres): todo lo que refleja la aprensión de unas masas desbordadas por la tecnología nacida de una ciencia incomprensible, y por ello objeto de desconfianza y temor. Muy rara vez tienen difusión e impacto de gran alcance películas que dan nuevo conocimiento o que elevan la apreciación de la cultura en cualquiera de sus aspectos. Es necesario alcanzar el mayor número posible de clientes de un producto no necesario: como consecuencia, debe buscarse el mínimo nivel común de exigencia y de preparación, para que nadie se sienta abrumado o sobrepasado por lo que se ofrece.

Con la televisión, todo lo que el cine había desarrollado para una experiencia relativamente poco frecuente y fuera del ambiente familiar, sc introduce en la intimidad de cada hogar. Es la manera más invasiva de someter a la persona a la lluvia casi ininterrumpida de mensajes explícitos o implícitos, ideológicos y comerciales, con todos los recursos gráficos, visuales, dramáticos, para conseguir el máximo impacto en el tiempo mínimo, sobre el mayor número posible de espectadores. La pantalla, con su torrente de palabras e imágenes llega a destruir la conversación de familia o amigos, la lectura de libros, la reflexión que necesita de soledad y silencio. Mientras podía suponerse que ir al cine era algo pensado, en cuanto a la elección de película y su oportunidad, y una vez terminada la sesión podría discutirse lo visto como una experiencia compartida y terminada, la TV es inagotable y omnipresente.

Los nuevos héroes de nuestro ambiente popular son los que la TV promueve; los productos que se convierten en símbolo de actualidad sociocultural son los que se ofrecen más insistentemente en sus programas. A su vez, la literatura de masas, en diarios y revistas sobre todo, se alimenta de los mismos temas y personajes de lo que alcanza popularidad en la televisión. Casi puede decirse que nada es "real" en un sentido práctico sino lo que se ve en su pantalla, y 
se pagan sumas enormes por tener unos segundos de fama o de soporte de un producto en un programa populat.

Aunque se habla de la "aldea global" de comunicación casi universal e instantánea mediante los teléfonos móviles, el fax, el acceso a internet, todo eso es de carácter más privado y puntual. Son los "medios de masas" por excelencia la televisión, cine, periódicos y revistas no-especializadas, y estos son los que moldean la "cultura" dando modos de pensar, de reaccionar, de decidir, para la inmensa mayoría de nuestra población de fines de siglo; un siglo que ha estado marcado por el desarrollo científico e industrial en aspectos positivos y negativos que se reflejan en esos medios.

\section{Características de los medios de masas}

La forma propia de todos los medios de comunicación destinados al gran público es la presentación dinámica, rápida y superficial de todo tema, por serio que sea y dificil de desarrollar con exactitud. Todo tiene que trivializarse y debe ser reducido a "bocados" asimilables sin esfuerzo, puesto que la exigencia de esfuerzo disminuirá el número de clientes. Se reduce la crítica de fuentes, la solvencia y objetividad de la información, el respaldo autorizado de opiniones: cualquier personaje de fama -en el mismo ambiente de los medios de masas-se convierte en experto digno de atención aun en campos totalmente ajenos a su preparación o actividad. Como no puede cansarse al público con una discusión razonada de un problema serio, se vuelve todo banal con paneles de discusión en que se da el mismo valor a la contribución ponderada de un estudioso reconocido y a la agudeza o trivialidad pueril de quien no tiene idea de lo que se discute. Nada se lleva a una conclusión lógica, sino que se cambia de tema y de punto de vista en forma tal que la impresión resultante es, casi siempre, de una total subjetividad sin criterio de verdad o de certeza.

La misma actitud, de buscar la máxima difusión mediante la norma de nivel mínimo, determina el contenido de los programas de TV o radio, y de los diarios y revistas populares. En lugar de centrar su atención en ideas o hechos, se busca siempre hablar de personas, del llamado "interés humano": políticos, gente del deporte, del mundo del arte, del dinero, subrayando siempre lo llamativo, extraño, trágico, real o supuesto, sustituyendo rumores y cábalas por información inexistente o poco interesante a la curiosidad morbosa que se quiere alimentar. Son el ejemplo más claro y común de este modo de actuar el llamado "periodismo amarillo", las "revistas del corazón", los programas de autorevelación en confesiones íntimas y de interés nulo para quien no quiera rebajarse a un mero 
chismorreo pueblerino. Se cumple exactamente la confesión cínica y dolorida de Lope de Vega:

Pues el vulgo lo paga, es justo / Hablarle en necio, para darle gusto.

Muy pocas páginas y muy pocas horas de los medios de masas se elevan por encima de estos niveles ínfimos. $Y$ aunque hay muchas voces que se levantan contra la "telebasura" saturada de violencia, sexo y materialismo comercial, parece cada vez más difícil conseguir un cambio de rumbo, pues se da una retroalimentación obvia: la saturación de lo que se ofrece al público con esos elementos vulgares, crea un ambiente en que solamente ese contenido es esperado y aceptado.

\section{Ciencia y seudociencia}

La ciencia y sus consecuencias tecnológicas han modelado la sociedad moderna, sobre todo en los dos últimos siglos. La producción de bienes, la medicina, las comunicaciones, la guerra, el empleo y sus consecuencias nacionales e internacionales, la educación, los mismos medios de masas de que estamos hablando, reflejan los avances científicos cada vez con mayor rapidez e impacto. Y lo hacen también los modos de pensar, que tienden a valorar como forma suprema del conocer el quehacer científico, la investigación experimental, elevando a rango de sabios universales a quienes como Einstein, Sagan o Hawking parecen simbolizar algún aspecto arcano de la ciencia, aunque no se comprenda su obra ni el verdadero alcance de sus aportaciones.

Del asombro ante el progreso científico y la insistencia sobre sus logros, se pasa con facilidad a la suposición reduccionista de que todo saber debe ajustarse a la metodología experimental de las ciencias de la materia. De ahí a un positivismo y materialismo más o menos explícito hay solamente otro paso imperceptible, que se manifiesta en el racionalismo que niega lo que no puede formularse en ecuaciones o medidas, y últimamente llega al ateísmo. Todo ello fomentado por la superficialidad que no quiere o sabe estudiar un problema a fondo ni distinguir usos analógicos o equivocos de términos técnicos o conceptos hipotéticos.

Entre los paradigmas científicos modernos, son especialmente objeto de interpretaciones pueriles y equivocadas la Teoria de la Relatividad y la Mecánica Cuántica, pilares de la Física, pero de dificil asimilación sin un estudio muy profundo, que nunca resuelve todos los problemas inherentes a sus conceptos básicos y a su posible fusión en una visión coherente del Cosmos. De la 
Relatividad, la cultura de masas no conoce sino su nombre, extrayendo de él la conclusión absurda de que "todo es relativo", con la interpretación subjetivista de que no hay verdad, sino opiniones igualmente válidas en cualquier campo y de cualquier autor. Es esto algo que encaja muy bien con las características ya mencionadas de los medios de masas, con sus discusiones de mesa redonda que nunca dejan nada claro ni distinguen entre hechos, hipótesis y elucubraciones arbitrarias. Hasta la misma ciencia se ve destruida por este relativismo, que se niega a aceptar hechos incontrovertibles cuando no se ajustan a ideas preconcebidas: "Yo ya tengo mis ideas: no me confunda Vd. con hechos".

De la Mecánica Cuántica se extrae la idea de cálculo probabilístico para negar certeza alguna y para suprimir el libre albedrío: todo ocurre por azar. Lo mismo se aplica a la evolución de estructuras en el Universo, de la vida y el Hombre, a los cambios en la sociedad humana. No hay causalidad a ningún nivel: todo ocurre "porque s?". Es la apoteosis de la irracionalidad, defendida en nombre de la racionalidad científica, que reduce al hombre y sus actividades a un mero actuar aleatorio de sus átomos. Quienes no buscan en la indeterminación su excusa, la encuentran en un determinismo materialista, que ve en el Hombre tan sólo el juego ciego y mecánico de fuerzas sin control alguno. En ambos casos se destruye la misma idea esencial del Hombre, de su naturaleza que busca Verdad, Belleza y Bien, con responsabilidad por sus actos libres que le hacen sujeto de derechos y deberes ante si mismo, la sociedad y el Creador.

Contra este fondo de ignorancia, relativismo, materialismo y superficialidad, es comprensible que se presente como ciencia lo que ningún científico serio considera digno de atención, o que se den noticias que tergiversan lo que hay de verdadero en alguna comunicación profesional. Podemos decir que, con muy contadas excepciones, lo que se ofrece al gran público está escogido y redactado por analfabetos científicos, que distorsionan todo lo que tocan, aun sin pretenderlo, con simple traducción equivocada de términos técnicos o en otra lengua, o con el deseo de dar mayor impacto a una noticia de poca "garra" periodística. Matizar una afirmación es diluir su efecto sobre los lectores o televidentes; comprobar las fuentes implica un retraso inaceptable. Ejemplos recientes de exageración o falta de conocimiento los tenemos en las noticias de hielo en la Luna, vida en el meteorito marciano, océanos ocultos bajo kilómetros de hielo en Europa, que dan lugar a titulares tan fantásticos como decir "iNo estamos solos!". Lo mismo es aplicable a cuadernos de imágenes presentadas como resultado de datos de la exploración espacial, cuando son realmente pura construcción imaginaria en un ordenador, realizada sin respeto alguno por los datos conocidos ni aun por la descripción en el texto que acompaña las figuras de colorido absurdo. 
Como muestrario de campos en que la ciencia se deforma hasta convertirse en seudociencia es posible mencionar, sin ser exhaustivo, los siguientes:

- se promueven "medicinas alternativas", con modas en dietética, remedios supuestos basados en magnetismo, luces de colores, "vibraciones", sustancias varias. Especialmente dirigidos a quienes sufren de dolencias crónicas $\mathrm{y}$ dificilmente curables, desde jaquecas hasta artritis. Aparte del daño económico y de falsas esperanzas, estos remedios pueden impedir la búsqueda de posibles ayudas médicas reales.

- sugiriendo "fuerzas ocultas" desconocidas para la ciencia oficial, se venden a los crédulos varios cristales, talismanes de buena suerte, anillos o collares con virtudes curativas o protectoras contra varias calamidades presentes o posibles. Pulseras metálicas, ámbar, cuarzo, son solamente una pequeña muestra de ese acervo de seudociencia supersticiosa.

- otras alternativas a la llamada "ciencia institucional" incluyen ovnis, misterios de la arqueología de diversas culturas, las leyendas sobre las pirámides de Egipto, los supuestos centros de energia en el Perú (Machu Picchu, Nazca), anomalías magnéticas (triángulo de las Bermudas), otras culturas de alta tecnología en pasados remotos (piedras de Ica, Atlantis), sanaciones y operaciones quirúrgicas por curanderos brasileños o filipinos (sin sangre ni cortes en el paciente), y todos los fenómenos de ESP (percepción extra-sensorial).

- ideologías místico-panteístas, especialmente de base hindú: karma, reencarnación, viajes astrales, sabiduria "cósmica" esotérica y mezclada con términos de la Física cuántica y relativista. Todo ello dentro de una obsesión por lo oriental, rebajando el valor de lo racional y lógico para buscar una iluminación superior a base de frases, palabras o gestos rituales, generalmente según el método de algún gurú o representante de escuelas antiguas y ocultas.

- adivinación del futuro (Nostradamus) y su control, con diversos tipos de cartas (tarot), hojas de té, I Ching, consulta de espíritus (Ouija), comunicación con los difuntos. Dentro de esta misma tendencia, la enormemente difundida superstición astrológica, con sus secuelas de negar o disminuir la responsabilidad individual para atribuir sucesos y modos de proceder a influjos astrales. Algo que se encuentra en la casi totalidad de los diarios y revistas populares.

- manipulación pretendida del mundo supra-humano: magia blanca, magia negra (mal de ojo), ritos para conseguir diversos efectos, desde un buen empleo hasta el amor (amarres, brujería). Apenas es creible que en una sociedad 
de fines de siglo se den tantísimas aberraciones de este tipo como indican los anuncios por palabras en los mejores periódicos y en las revistas esotéricas de nuestros quioscos.

- en el campo más estrictamente científico: es común la exageración sensacionalista, con un clima de catastrofismo inminente. Conjunciones planetarias, cometas, meteoritos, se anuncian en términos apocalípticos, con un fondo subyacente de milenarismo y numerología que busca fechas especiales para cambiar la historia o la vida humana.

- la ecología es también campo abonado para la predicción de peligros o calamidades. Todo se ve como un peligro; las centrales nucleares, las de carbón, las hidroeléctricas, los aparatos de microondas, los teléfonos móviles, el tendido eléctrico. Mientras se atacan todos los medios de producción de energía, no se propone alternativa viable ni de aplicación suficiente, universal y no contaminante. Todo aquello que no se entiende aparece como siniestro, produciendo "radiación" interpretada automáticamente como equivalente a la que emana de productos radioactivos y de las explosiones atómicas. Se olvida el hecho básico de toda interacción biológica, que se da un umbral por debajo del cual no hay daño alguno, como no causa una quemadura el agua tibia por mucho tiempo que actúe sobre la piel. Así se anuncian los peligros del azúcar, la sacarina, la grasa, la sal, el cloro, los plásticos, el radón del suelo, basándose en dosis extremas sin comparación con las cantidades del uso real de cada ingrediente o con factores ambientales presentes desde hace millones de años en nuestro entorno.

- tema frecuente para la seudociencia es la supuesta incompatibilidad de ciencia y religión, especialmente la fe cristiana. No se perdona a ésta su "dogmatismo", pues el presentar algo como verdad inmutable recibida de Dios choca frontalmente con la actitud relativista de mesa redonda en que todas las opiniones, aun las mảs descabelladas y sin fundamento alguno, deben admitirse como de igual valor. La vaciedad intelectual se hace sinónimo de apertura mental, llegando algunas veces a discutir la validez de verdades matemáticas evidentes por su misma formulación, con una especie de reacción automática contra toda certeza.

Esta descripción sucinta del efecto de los medios de masas sobre la cultura científica de nuestra época, con sus consecuencias sobre el modo de pensar de las poblaciones de formación educativa de nivel medio o bajo, no es suficiente ni para establecer causas ni para proponer remedios. 
En países de regímenes autocráticos es común que el gobierno controle totalmente los medios de masas; aun sin llegar a tal extremo, es dudoso el beneficio de que haya Radio, TV, diarios, con un patrocinio abierto o solapado del poder público: claramente puede esperarse una actitud servil de tales medios hacia aquellos organismos o personas que los mantienen en existencia. En los campos de decisión político-social, faltará la debida objetividad imparcial para que los ciudadanos evalúen actuaciones o leyes que tienen gran importancia para el bien individual y común. Todo esto se ha visto y se ve claramente en la historia reciente de regímenes comunistas, que reproduce casi a la letra la sátira sobrecogedora de Orwell en su novela "1984", con la presencia constante del líder en todas las facetas de la vida y su tergiversación de términos para decir lo opuesto de lo que significan las palabras: los medios de comunicación son medios de un indoctrinamiento que puede llegar a ser un "lavado de cerebro" constante.

Donde la utilización de medios de masas es libre, y sujeta a las presiones de mercado, son los intereses de grupos económicos o de ideologías concretas los que definen el contenido y punto de vista de lo que se ofrece al público. Materialismo consumista, posturas de libertarismo absoluto (por ejemplo, en lo relativo a la sexualidad, el aborto y la eutanasia) se promueven con una pretendida objetividad científica. Con el mismo título se rebaja la dignidad del hombre en relación a los animales (evolucionismo radical) hablando de "derechos" de insectos, plantas o montañas, aun en perjuicio de seres humanos. Con el pretexto de preservar "culturas" primitivas, se promueve la reducción de tribus a meras reservas -casi de parque zoológico- para satisfacer el deseo de investigación de algún antropólogo o sociólogo.

Con la misma asepsia ética, se habla de manipulación genética, de bebésprobeta a usar en experimentos o para trasplantes de órganos, como si el decir que se hace con fines cientificos fuese suficiente para justificar cualquier aftenta a la dignidad humana de aquellos que no pueden defenderse. La vieja falacia de que "el fin justifica los medios" termina por presentar al ser humano como cobaya de laboratorio o animal de granja, "útil" o no para una sociedad de supuesta igualdad democrática, pero que no quiere proteger a los débiles, a los que no tienen voz pública, a los que estorban.

Instituciones $\tan$ básicas como el matrimonio se desvirtúan en su misma esencia, presentando como de igual valor el compromiso de fidelidad que garantiza el entorno adecuado para los hijos y el mero cohabitar de las "parejas de hecho" unidas por un instinto meramente animal y pasajero. Más absurdamente todavía, se habla de "matrimonio" entre homosexuales, con "derecho" a adoptar hijos que sufran las consecuencias de ese entorno aberrante, solamente para 
satisfacer el capricho egoísta de unos adultos que no encuentran al fin sino un vacío en esas relaciones estériles por naturaleza.

Hasta las noticias estrictamente científicas en el campo de la Astronomia, donde el conocimiento parece estar a salvo de toda manipulación tendenciosa, se utilizan para rebajar la autoestima humana dando como obvio (aun en contra de la ciencia verdadera) que el Universo está Ileno de vida inteligente superior a la terrestre, o insistiendo en la hipótesis-descartada por los datos actuales- de un Universo eterno, infinito, tal vez cíclico y últimamente sin sentido ni razón de ser.

Lo mismo puede escucharse repetidamente con respecto a la mal llamada "inteligencia artificial" que se supone suplantará a la inteligencia humana, reducida a una consecuencia material de aumentar el número de neuronas en un cerebro de primate. Así se sientan las bases para la devaluación del Hombre, puro animal o máquina finalmente superable por una tecnología que siempre se ve como la solución futura de todas las limitaciones y problemas. Todo en favor de una "sociedad" utópica en que todo se reduce a derechos de los más fuertes y más desarrollados económicamente, sin limitaciones éticas o racionales.

Es difícil juzgar hasta qué punto este coro de voces insistentes responde a un plan preconcebido de reducir el hombre a una "cosa" con pretextos científicos, para fines de control social cada vez mayor o para promover filosofías materialistas que hagan el juego a intereses monetarios. Tal vez sea más una cuestión de ignorancia atrevida y de buscar lo llamativo, sensacionalista y de nivel infimo para alcanzar mayor número de clientes; de cualquier forma, el efecto es enormernente nocivo, para el individuo y para la sociedad.

En otros países, tan acérrimamente defensores de la libertad como los Estados Unidos, se regula la publicidad, e incluso la presentación de revistas en público, para no permitir lo obsceno en materiales expuestos a todas las miradas, aun de niños. Tampoco se permiten programas de TV de contenido escabroso en horas durante las cuales es de suponer que los menores de edad serán parte normal de la audiencia. Tal vez fuese necesario ejercitar un control parecido sobre el contenido de tergiversaciones y falsedades seudocientíficas, por lo menos con una indicación semejante a la que se obliga a poner en los anuncios de tabaco: este material puede ser nocivo para la salud psicológica y mental del consumidor.

Como mínimo, sería lógica la prohibición de engañar y perjudicar al público con todos los anuncios de productos de propiedades curativas a beneficiosas que no están respaldadas por pruebas de laboratorio debidamente controladas: esto incluiría desde hierbas y amuletos hasta prácticas de gimnasia o 
regímenes basados en teorías sin efecto comprobable. Un defensor del consumidor en forma preventiva haría más labor beneficiosa que quien le protege de fraude o fallo después de la compra de un aparato.

Últimamente, es necesaria mayor educación, mayor cultura real de formación lógica y crítica, para que los que están sometidos al constante bombardeo de los medios de masas mantengan su independencia intelectual y su capacidad de distinguir lo verdadero de lo irracional. Sería la más hiriente ironía que el desarrollo de tecnologías de comunicación de alcance universal, capaces de elevar el nivel educativo de toda la humanidad, basadas en la utilización rigurosa de pensamiento lógico y su comprobación científica, diese lugar a una sociedad sin lógica ni criterio para aceptar la ciencia y desechar sus caricaturas. Aún más triste sería el vernos abocados a un mínimo nivel adocenado, de superstición tribal, de engaño interesado, porque "el número de los necios es infinito" y a ellos se dirigen las maravillas técnicas, fruto de mentes privilegiadas por su claridad y su trabajo. No es así como queremos entrar en el nuevo siglo, donde sin duda nos esperan todavia nuevas formas de comunicación con el potencial de hacer a todo habitante del planeta el hombre completo que antes era patrimonio exclusivo de la aristocracia.

Dr, P. Manuel M. Carreira, S.J. Astrofísico, Filósofo y Teỏlogo Universidad de Comillas - Madrid y Cleveland (USA). 